\title{
Energy consumption between routing and bridging protocol for eco- friendly wireless networks
}

\author{
Rinanza Zulmy Alhamri ${ }^{\star 1}$, Toga Aldila Cinderatama ${ }^{2}$, Agustono Heriadi $^{3}$, Andika Kurnia Adi Pradana ${ }^{4}$ \\ Politeknik Kediri, Indonesia ${ }^{1,2,3,4}$
}

\author{
Article Info \\ Keywords: \\ Energy Consumption, Routing, Bridging, \\ Wireless Network
}

\section{Article history:}

Received 30 March 2019

Revised 25 June 2019

Accepted 29 July 2019

Published 30 July 2019

\section{Cite:}

Alhamri, R., Cinderatama, T., Heriadi, A., \& Pradana, A. (2019). Energy Consumption Between Routing and Bridging Protocol for Eco-Friendly Wireless Networks. Kinetik: Game Technology, Information System, Computer Network, Computing, Electronics, and Control, 4(3).

doi:http://dx.doi.org/10.22219/kinetik.v4i3.800

* Corresponding author.

Rinanza Zulmy Alhamri

E-mail address:

rinanza.z.alhamri@gmail.com

\begin{abstract}
The implementation of eco-friendly technology has been become an interesting field for sustainability. No exception with the implementation of wireless technology that used for developing networks infrastructure, it is necessary for saving the usage of energy. As a data forwarding protocol in a computer network, commonly there are two protocols that used for, which are routing and bridging protocol. Technically routing protocol has been confirmed that it is more effective and efficient than bridging protocol. However bridging protocol still becomes the popular protocol for data forwarding because it is easy to use. This research tried to test the energy consumption of the wireless network device that implementing between routing or bridging protocol. The wireless network device that used for this research was MikroTik router RB 433Ah. The data forwarding protocol that was tested consists of bridging, static routing, and RIP routing. Data traffic scenario that used for this research consisted of two scenarios which were HTML data access with packet size 256B and video streaming data access with packet size 1518B. Measuring the energy consumption referred to three parameters which were power consumption, CPU usage, and processor temperature. The result showed that for HTML data access scenario, the RIP routing protocol become the lowest energy consumption with power consumption reached $7.460 \mathrm{~W}$, CPU usage $4.6 \%$, and processor temperature $38.133^{\wedge} \mathrm{C}$. While for video streaming scenario, generally the RIP routing protocol still become the lowest energy consumption with power consumption reached $7.567 \mathrm{~W}, \mathrm{CPU}$ usage $7.33 \%$, and processor temperature $36.727^{\wedge} \mathrm{C}$.
\end{abstract}

\section{Introduction}

Wireless networks are the most considered choice today to build infrastructure computer networks, especially for wide coverage areas. This is because wireless networks allow users to connect the networks flexibly without being limited by hardware like the limitation of conventional wired computer networks. Finally, wireless networks infrastructure is be able to cover almost every places even remote places. There has been increased the use of mobile devices, hotspot areas, and wireless loT globally [1]. Even wireless infrastructure like telecom tower (BTS), has grown significantly. In 2018, there are 118 thousand towers that cover mostly $95 \%$ area of Indonesia for serving 157 million customers [2]. Actually, mobile device that implements wireless technology infrastructure gives energy efficiency, but nowadays the increasing of data usage makes energy saving in vain [3]. It is no doubt that the increase of internet conection and mobile phones impacts the electricity consumption especially in developing country [4].

In other hand, the development of wireless networks as information and communication technology (ICT) certainly raises an effect [5],[6]. Theoretically, information and communication technology has a positive and significant relation with energy consumption [7], no exception with wireless technology. Wireless technology is one of the developed technology that significantly increases its energy consumption [8]. It is because wireless communication need more power to do RF transmission for transferring the data [9]. That is why it is needed to control the energy consumption in network devices especially wireless infrastructures. Eco-friendly technology can provide a significant contribution in order to avoid the crisis of non-renewable energy [10],[11]. It is imperative for current technology like wireless networks infrastructure to build awareness for saving the energy. For this reason, more attention is needed to use wireless technology that is be able to save energy and eco-friendly. Energy saving is a global issue today. It is needed a strategy to save the energy for operating the ICT business include wireless technology [12], rather than debating what kind of technology that saves the energy [13].

Power consumption of network devices does not have any relation with the bandwidth condition, but it has relationship with the configuration of the device [14]. The network device configuration includes how data forwarded, the size of the packet, and what operation mode the device to be. Indeed, one thing that should be considered for choosing the wireless technology configuration is the protocol of forwarding data. The use of data forwarding protocols

Cite: Alhamri, R., Cinderatama, T., Heriadi, A., \& Pradana, A. (2019). Energy Consumption Between Routing and Bridging Protocol for Eco-Friendly Wireless Networks. Kinetik: Game Technology, Information System, Computer Network, Computing, Electronics, and Control, 4(3). doi:http://dx.doi.org/10.22219/kinetik.v4i3.800 
on a network device has been confirmed that it can impact the energy consumption [15],[8],[14]. Actually, there are two common protocols that are widely used in developing a network, it is called routing and bridging protocols [16]. Bridging itself is a layer 2 protocol that is used to forward data which refers to the frame of the Media Access Control (MAC) address, while routing is a layer 3 protocol that is used to forward data which refers to the Internet Protocol (IP) address packet [17]. Both have the same functions, but have different performance actually. Routing protocols can work smarter than bridging protocol. In performance, the routing protocol is certainly more efficient in carrying out data forwarding because it is able to forward data to the intended destination. Routing protocol also is more dynamic because it can be set the algortihm for energy saving needed [18]. But in reality, the application of bridging is more simple and easier in configuration, which is not as complicated as the configuration of routing protocols [19]. This is what makes the implementation of bridging still popular today compared to the application of routing protocols.

This study wants to know the advantages of routing and bridging protocols in relation with the eco-friendly wireless technology. Testing based on scenario simulations is the right approach to prove what data forwarding protocols are the best for saving the energy in wireless networks, whether bridging protocol or routing protocol. For this reason, it is necessary to have a direct and comprehensive study to test the capabilities between routing and bridging protocols in saving energy. There were a lot of related research had been done. Baliga in 2011, investigated the energy consumption in wired and wireless access network [9]. It focused for how much the power consumption has been used by the type of network technology such as DSL, HFC, PtP UTMS and WiMAX. The result said the optical based wired access has the lowest and stable power consumption especially optical PtP. For the high-power consumption was wireless access especially WiMAX. This research only focused the networks topology for daily consumer use. It was not detail for the use of data forwarding protocols.

Power consumption of router had been done by Morelli et al. in 2012. It focused to measure the power consumption of router devices that implementing some operation mode such as idle mode, static routing, RIPv2, and OSPF [8]. The result is RIP has the highest power consumption than OSPF. The idle mode had lowest power consumption. In the same year, Morelli at al. also studied [20] the energy consumption of wireless network access point. Power consumption was measured referred to wireless protocol configuration of IEEE $802.11 \mathrm{a} / \mathrm{b} / \mathrm{g} / \mathrm{h}$. The result said that the higher capabilities could need more power consumption. Actually Morelli et al. research [8] did not concern to wireless networks, while Morelli et al. other research [20] concerned just about the brand of wireless access point.

In 2014 Park and Han [15] conducted a study aimed to measure and to model power consumption on the interface of a router device. The test used a scenario that refers to the RFC2544 standard. The data forwarding protocols tested includes Bridge, OSPF, and BGP. The result was the use of routing using the BGP protocol had the lowest power consumption at various package sizes. Like [8], this study only used wired networks protocols without bridge protocol using RFC2544 scenario.

Jimenez et al. in 2016 [21] conducted a study to create an Open Flow based Software-Defined Network (SDN) program that was able to control the access point in order to save power consumption. By using the SDN, the access point was expected be able to activate itself automatically in accordance with predetermined threshold conditions. The results of the research carried out succeeded in reducing power consumption used in normal use that saved in power consumption reach up to $50 \%$ of normal use. This study was done using simulation, not in real networks.

In 2017, Jacome et al. [22] aimed to measure power consumption in routing protocols using virtualization and simulation methods. Routing protocols on mobile communication was run in virtual environment. From the results of the study conducted, it was found that the CPU usage for video streaming between routers using OSPF and RIPv2 had the same percentage. Whereas CPU usage for HTTP traffic data, RIPv2 was greater $10 \%$ than OSPF. While about the use of power consumption has been proven that the most energy saving is RIPv2 protocol.

In this study, an empirical examination of the comparison of energy consumption used between routing and bridging protocols will be carried out as a form of recommendation towards implementing eco-friendly wireless networks. By knowing what protocol that has low power consumption in a wireless networks, it is hoped that eco-friendly wireless networks can be applied to support sustainable energy in information and communication technology. The results can be used for the configuration decision to implement wireless networks for the wireless device. The strategy of energy saving is emerged because of the impact of ICT technology [5].

\section{Research Method}

To get a good result, this study implemented a simple wireless network based on MikroTik device. The wireless network forwarded some data traffic scenario as simple as data could be carried from one host to another. When the wireless network work well, measurement was done on the device in every scenario. This section will be explained how this study was done.

From Figure 1 the research began with adjusting the environment of the device tested according to Energy Consumption Rating (ECR) initiative and Alliance for Telecommunications Industry Solution (ATIS). The study was continued with early measuring for the idle networks device such as power consumption, CPU usage, and processor temperature. After early measuring and then determining what data forwarding protocols used first and then followed

(C) 2019 The Authors. Published by Universitas Muhammadiyah Malang

This is an open access article under the CC BY SA license. (https://creativecommons.org/licenses/by-sa/4.0/) 
by configuring the networks. If the networks could work properly according to the data forwarding protocol used, the study was continued with determining the traffic simulation according to RFC2544 that included packet data for 256B and 1518B. After the traffic could work using FlowGrind generator, the networks device then measured for $150 \mathrm{~s}$ where sampling was taken every $10 \mathrm{~s}$. This method was done in every data forwarding protocols and every traffic scenario. The final measurement deducted power consumption, CPU usage, and processor temperature for each scenario.



Figure 1. Research Method

\subsection{Topology}

The basic idea of the topology for this study was taken for network that could simply carry the data traffic from one host to another host using forwarding data protocol. Simple wireless Point to Point (PtP) networks was a good idea since the study only needed the measurement of the device when it was running. PtP connection was able to become the backbone for wireless networks to support large bandwidth of data traffic [23]. After that PtP had a stable power consumption [9], so that this topology was neutral for basic of wireless networks topology. Even though the topology was simple, by using scenario of the data traffic generator, it could be able as well as real condition. As long as the wireless network topology could carry the data traffic using forwarding protocols perfectly, the measurement of energy consumption on the device could be done properly. The data traffic scenario will be explained detail on next section. The topology that used for this study is shown at Figure 2. As Figure 2 shown, there were two hosts that could communicate with each other through the wireless device. Those two hosts were PC A and PC B.

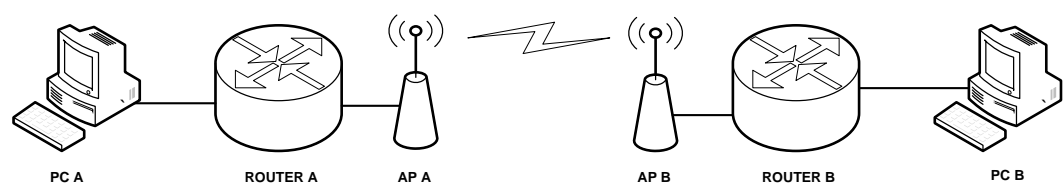

Figure 2. Topology for Implementing Wireless Network Testing

PC A was connected with router $A$, which directly connected with wireless $A$. While PC B connected with router $B$ which the router directly connected with wireless $B$. Then between wireless $A$ and wireless $B$ was connected physically so that both router could communicate using forwarding data protocol. From that point, PC A could communicate with $\mathrm{PC} B$ and vice versa through the wireless router devices. By using router device, the topology could be able to implement

Cite: Alhamri, R., Cinderatama, T., Heriadi, A., \& Pradana, A. (2019). Energy Consumption Between Routing and Bridging Protocol for Eco-Friendly Wireless Networks. Kinetik: Game Technology, Information System, Computer Network, Computing, Electronics, and Control, 4(3). doi:http://dx.doi.org/10.22219/kinetik.v4i3.800 
some data forwarding protocols. While the wireless device, it could carry the data traffic from one access point to another station without using some wire like todays trend. In order to make the network could run perfectly, wireless $A$ that connected with router A had a role as an access point (AP), and wireless B on router B has a role as a station [24].

\subsection{Hardware and Software}

This study needs hardware and software that is suitable for the condition of the developed wireless networks. Because the study used a simple wireless network, the required hardware and software was easy to find. For the hardware, this study needed 2 PCs, 2 routers, 2 wireless devices, and 2 pieces UTP LAN wire. Fortunately for the router device, this study used a router that had become into one bundled with wireless interface. It was MikroTik that made a routerboard which had wireless feature, so that it could forward the data via wireless without adding some external peripheral. Detail specifications of the hardware is following.

1. Computer: CPU 2.4GHz, RAM 2GB, with LAN card interface 10/100 MBps.

2. Router: MikroTik RB433Ah with CPU 680MHz, RAM 128MB

3. Wire: 1 meter UTP 100BaseT with RJ45 connector.

MikroTik RB 433Ah has three ethernet interfaces with 10/100 MBps. It has mipsbe architecture and it is equipped with 3 MiniPCI slots, so that wireless peripheral is installed directly with the router. By using CPU $680 \mathrm{MHz}$ and RAM $128 \mathrm{MB}$, theoretically RB 433Ah just need maximum power consumption $4.3 \mathrm{Watt}$ and if it is without any attachment, it can run in 3 Watt. For the features, the router is equipped with RouterOS using license level 5 . Besides cheap and easy to find, MikroTik RB 433Ah can work appropriately as advance network proposes. It can become central part of the network because it can operate as repeater, bridge, router, firewall, NAT, access point, and hotspot. With those many features, MikroTik RB433Ah is suitable as a router for developing simple wireless network in this study and it can perform data forwarding protocols includes bridging and routing [25].

The required software is also adjusted with the conditions of the network. Because it was used a PC as a host, it was needed an operating system to make the PC could work properly and so did the router, it was also needed an operating system to make the router could work properly. Finally, for the scenario purpose, it was needed a software that could generate data traffic like real traffic condition. For those needed software, here are the software needed to develop a wireless network for this study:

1. PC operating system: Debian 7 "Wheezy" 32 bit non GUI.

2. Router operating system: MikroTik RouterOS 5.2 mipsbe license level 5.

3. Data traffic generator: FlowGrind.

It was used Debian Wheezy non GUI for the operating system of the computer, because it just needed low memory requirement, and actually Debian is well-known for the best Linux server todays. On router, RouterOS 5.2 with license level 5 was default operating system for MikroTik RB 433Ah, so it was standard for wireless network developing. FlowGrind as advance TCP traffic generator was Linux software that could be installed properly on Debian. FlowGrind was used to test and benchmark using a lot of measurement tools such as throughput, metric, and report for a network.

\subsection{Required Environment Condition}

Before the wireless networks performed the scenario and it was measured, this study needed to make sure that the hardware worked in an ideal condition, so it was expected that the hardware devices could run properly. It was important since the environment affected the precise of the power consumption measurement. The condition of the environment where the hardware running was adjusted as well as the condition standard referred to ECR and ATIS [15]. The environment where the hardware running should be in accordance to Table 1. In ECR and ATIS column that shown as follows the temperature should be in $25^{\wedge} \mathrm{C}+/-3^{\wedge} \mathrm{C}$, the humidity should be between $30 \%-75 \%$, the barometric pressure should be between $812-1020$ mbar, and AC power should be in $230 \mathrm{~V}+/-1 \%$. The hardware of wireless networks, especially the router should be in idle condition to adapt for 4 hours to make the router run properly.

Table 1. ECR and ATIS Environment

\begin{tabular}{lll}
\hline Condition & ECR and ATIS & Actual \\
\hline Temperature & $25^{\wedge} \mathrm{C}+/-3^{\wedge} \mathrm{C}$ & $24^{\wedge} \mathrm{C}$ \\
Humidity & $30 \%-75 \%$ & $75 \%$ \\
Barometric Pressure & $812-1020 \mathrm{mbar}$ & $979 \mathrm{mbar}$ \\
AC Power & $230 \mathrm{~V}+/-1 \%$ & $230 \mathrm{~V}$ \\
\hline
\end{tabular}

As shown at Table 1 in actual column, this study was success to make an environment condition in accordance with ERC and ATIS standard. The condition of temperature was in $24^{\wedge} \mathrm{C}$, humidity was in $75 \%$, barometric pressure was in 979 mbar, and AC power was perfectly in $230 \mathrm{~V}$. Those meant the actual environment had values that matches with ERC and ATIS standard. So that this study could perform precisely measurement of the hardware power consumption that had run properly in an ideal environment condition.

(c) 2019 The Authors. Published by Universitas Muhammadiyah Malang

This is an open access article under the CC BY SA license. (https://creativecommons.org/licenses/by-sa/4.0/) 


\subsection{Measurement}

This study measures the performance of the wireless router as the center of wireless networks. There were three parameters that measured to the running router, which were power consumption, CPU usage, and processor temperature [3],[4],[26]. Those three parameters represented as how far the energy is consumed by the router and then determining the level of eco-friendly wireless networks. Power consumption was the electricity energy needed for router device to work that measured in Watt unit. CPU usage was the percentage to describe how much the processor was working. CPU usage depended on the types of the tasks that are being performed by the processor. While processor temperature was the temperature of the main processing unit in router when it was working. The temperature measured in Celsius unit.

Because there was two routers on the topology of wireless networks in this study, so it was chosen one of them to be measured. To retrieve the power consumption of router, it was used wattmeter that could detect the power consumption of the router in every second. CPU usage could be seen in the resource feature of RouterOS in MikroTik RB433Ah itself. To measure the temperature of router processor, it was measured manually by checking the router processor using infrared thermometer. To make the measurement possible to perform, Figure 3 shows how the device installed include measurement tools together with the wireless network.

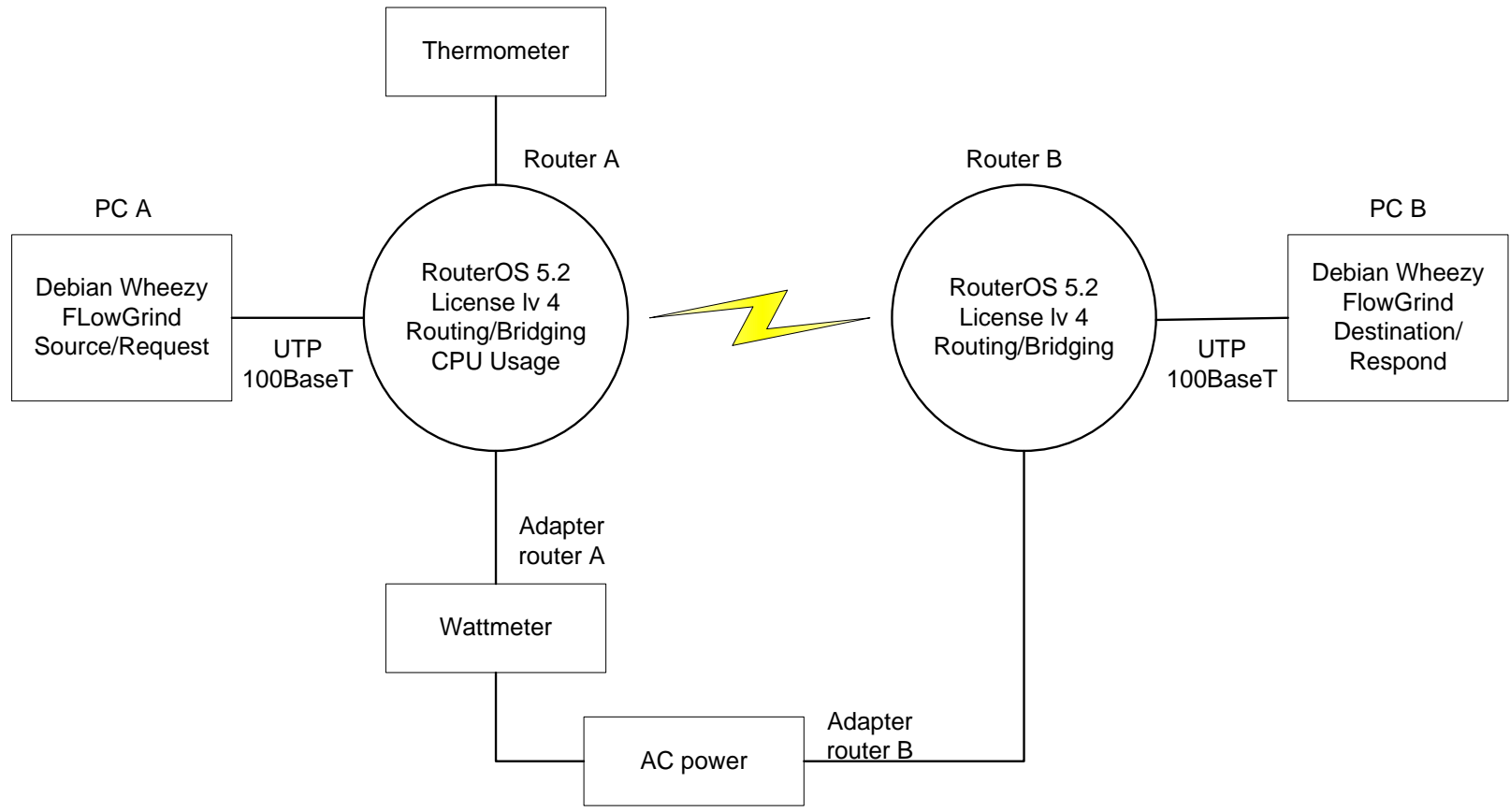

Figure 3. Implementation of Device Testing

From Figure 3 shows that measurement tools were installed on the one of the router in networks. For this research router A became a device network that measured for the power consumption, CPU usage, and processor temperature. Wattmeter was installed between router A adapter and AC power, so that wattmeter could check the electrical needed. Also router $\mathrm{A}$ was monitored for the resource to see the CPU usage. Checking the processor temperature manually also focused on router $A$. Energy consumption measurement was performed when the wireless networks was running in every scenario. Testing scenario started when data traffic from PC A could be received by PC B and vice versa, through router $A$ as an Access Point and router $B$ as a Station. Data forwarding protocols that was used by the router should be suitable with the expected scenario. The router surely could use both routing and bridging protocols over wireless networks. For detail about the scenario, it will be explained in the next section.

Measurement was performed when the router run in every testing scenario. The router run for 150 seconds in every testing scenario and it was taken sampling period in every 10 seconds [2]. Each measurement consisted of three measurement parameters included power consumption, CPU usage, and processor temperature. So that it recorded 15 times to measure the router in each testing scenario. And the value of measurement would be counted to obtain the average value that is like following Equation 1.

$$
\bar{A}=\frac{\sum_{i=1}^{n} B_{i}}{n}
$$

Cite: Alhamri, R., Cinderatama, T., Heriadi, A., \& Pradana, A. (2019). Energy Consumption Between Routing and Bridging Protocol for Eco-Friendly Wireless Networks. Kinetik: Game Technology, Information System, Computer Network, Computing, Electronics, and Control, 4(3). doi:http://dx.doi.org/10.22219/kinetik.v4i3.800 
Kinetik: Game Technology, Information System, Computer Network, Computing, Electronics, and Control

From Equation 1, $\mathrm{A}$ is the average value of measurement, $\mathrm{B}$ is a value of measurement in data number of $\mathrm{i}$. $\mathrm{i}$ is the increment performed from the beginning until number of $n$. And $n$ is number of measurement performed. Form average value of measurement will get result from the level of eco-friendly wireless network. It means what scenario for router that can run in low energy consumption will be retrieved. To make a result, it assumed that for value with higher power consumption, higher CPU usage, and higher processor temperature, it means higher energy consumption. Comparison of the value for every testing scenario will be explained in next section.

\subsection{Testing Scenario}

The testing scenario that was carried out in this study could be described with matrix of 2 dimensions. First dimension was the main testing scenario because it was about the use of data forwarding protocols. The router performed one of the data forwarding protocols to carry data traffic in the wireless networks. For this study, the data forwarding protocols that were implemented are bridge protocol, static routing protocol, and RIP routing protocol [4]. While second dimension in this matrix of testing scenario was the types of data traffic. For this study there were 2 types of data traffic testing scenario which were HTTP data access and video streaming data access [1]. The type of data access will influence how the traffic of data flows in the network.

Table 2. List of Testing Scenario

\begin{tabular}{|c|c|c|}
\hline \multirow{2}{*}{ Protocol } & \multicolumn{2}{|c|}{ Data Access } \\
\hline & HTTP & Video Streaming \\
\hline RIP & $\begin{array}{c}\text { Packet Format Size } \\
256 \text { B }\end{array}$ & $\begin{array}{c}\text { Packet Format Size } \\
1518 \text { B }\end{array}$ \\
\hline Static Routing & $\begin{array}{c}\text { Packet Format Size } \\
256 \text { B }\end{array}$ & $\begin{array}{c}\text { Packet Format Size } \\
1518 \mathrm{~B}\end{array}$ \\
\hline Bridging & $\begin{array}{c}\text { Packet Format Size } \\
256 \text { B }\end{array}$ & $\begin{array}{c}\text { Packet Format Size } \\
1518 \mathrm{~B}\end{array}$ \\
\hline
\end{tabular}

From Table 2, for each data forwarding protocol, would implement the types of data access. With three data forwarding protocols in first dimension and two types data access in second dimensions, it meant there was 3 by 2 ( $3 \times 2)$ matrix of testing scenario. So that, the measurement of energy consumption was performed 6 times as well as the testing scenario. Referred to RFC2544 about testing and benchmarking a network, this study used a testing scenario using the packet size of 256 Bytes for representing HTTP access and 1518 Bytes for representing video streaming access [27].

\subsection{Implementation}

After the topology of simple wireless networks as shown at Figure 2 has been ready, all of the hardware are activated. As early explanation, there were two wireless routers in the networks that one router as access point and another router as station. That two routers were confirmed for connected physically with wireless configurations as shown at Table 3.

Table 3. Wireless Configuration

\begin{tabular}{ccc}
\hline Attribute & Router A & Router B \\
\hline Mode & ap-bridge & Station \\
Band & $5 \mathrm{Ghz}$ & $5 \mathrm{Ghz}$ \\
SSID & MikroTik & MikroTik \\
Wireless & 802.11 & 802.11 \\
protocol & & \\
Others & Default & Default \\
\hline
\end{tabular}

Before the testing scenario was performed, it should be make sure that all the hardware run and the measurement tools were installed properly. All of required software were already installed especially data traffic generator FlowGrind on each PC. Then it was also confirmed that the environment around the running hardware was being as suitable as the ERC and ATIS standards. It made sure that the hardware had been run for 4 hours to adapt the condition. For comparison, the router that focused for measurement was measured for idle condition as shown in Table 4.

Table 4. Idle Condition of Router

\begin{tabular}{cc}
\hline Parameters & Idle Values \\
\hline Power consumption & 5.8 Watt
\end{tabular}

(C) 2019 The Authors. Published by Universitas Muhammadiyah Malang

This is an open access article under the CC BY SA license. (https://creativecommons.org/licenses/by-sa/4.0/) 


$\begin{array}{cc}\text { CPU usage } & 0 \% \\ \text { Processor } & 34^{\wedge} \mathrm{C} \\ \text { temperature } & \end{array}$

After early measurement was done for the idle condition, then it was performed the scenario testing. The first performed testing scenario was focused on how the router can forward the data using a protocol. So that data forwarding protocol configuration was implemented on each router in the networks. As early explanation in the before section there were three testing data forwarding protocols which are bridge, static routing, and dynamic routing RIP. For each data forwarding protocol would be different configuration for the protocols even the IP addressing. The configuration based on MikroTik environment using RouterOS in each router. In each testing implementation of data forwarding protocol, the second testing would be performed. The second testing scenario was about the flows of data traffic which were represented by HTML data access and streaming video data access. To make the data traffic like expected testing scenario, it was used FlowGrind software.

$$
\begin{aligned}
& \text { flowgrind }-H \text { s=xx ,d=yy }-G \text { s=q:C:256000 }-G s=p: C: 256000-T s=150 \\
& \text { flowgrind }-H s=x x, d=y y-G s=q: C: 1518000-G s=g: N: 1.518: 0.001-T s=150
\end{aligned}
$$

Equation 2 and Equation 3 were the script for FlowGrind to adjust the flows of data traffic as match as the expected testing scenario. Value $\mathrm{xx}$ and $\mathrm{yy}$ from those formulas meant that $\mathrm{xx}$ was source address and yy was destination address. Began with Equation 2 that was used for HTML data flow with the package size from request is 256 Bytes constantly and from response was 256 Bytes constantly which the traffic runs for 150 seconds. While Equation 3 was used for video streaming data flow with the package size from request was 1518 Bytes constantly and from response, there was normal gap with bitrate encode in $1518 \mathrm{~B} / \mathrm{s}$ which the traffic runs for 150 seconds.

\section{Results and Discussion}

The discussion described based on testing data size scenarios includes HTML access scenario with 256 B data package size and video streaming access scenario with $1518 \mathrm{~B}$ data package size. From the results of testing measurements of each scenario on a wireless networks in this study, values have been obtained from power consumption, CPU usage, and processor temperature that shown in Table 5.

Table 5. Result of Energy Consumption Measurements

\begin{tabular}{ccccccc}
\hline \multirow{2}{*}{ Protocol } & \multicolumn{3}{c}{ HTML (256 B) } & \multicolumn{3}{c}{ Video Streaming (1518 B) } \\
\cline { 2 - 7 } & $\begin{array}{c}\text { Power } \\
(\mathrm{W})\end{array}$ & CPU (\%) & Processor (C) & Power (W) & $\begin{array}{c}\text { CPU } \\
(\%)\end{array}$ & $\begin{array}{c}\text { Processor } \\
(\mathrm{C})\end{array}$ \\
\hline Bridge & 7.507 & 8.333 & 40.273 & 7.573 & 7.773 & 38.340 \\
Static & 7.500 & 5.667 & 38.673 & 7.573 & 7.667 & 36.367 \\
RIP & 7.460 & 4.600 & 38.133 & 7.567 & 7.333 & 36.727 \\
\hline
\end{tabular}

From Table 5, It can be taken an analysis that the use of the bridge protocol as a data forwarding protocol on HTML access (request-response) has the highest average value of power consumption, CPU usage, and processor temperature. Whereas static routing protocols have an average value of power consumption, CPU usage, and processor temperatures in the lower order. And the RIP routing protocol has the lowest value of power consumption, CPU usage, and processor temperature of all. With the low electricity consumption, CPU usage, and temperature of the processor produced by the RIP protocol. From this result, it makes that RIP routing protocol becomes an eco-friendly protocol in data forwarding on HTML access testing scenario with power consumption reaches 7.460 Watt, CPU usage reaches $4.600 \%$, and processor temperature reaches $38.133^{\wedge} \mathrm{C}$.

For video streaming access scenario, the highest power consumption, CPU usage, and processor temperature are experienced by bridge data forwarding protocols. Whereas the lowest power consumption, CPU usage, and processor temperature is the RIP routing protocol even though the processor temperature produced is higher than the static routing protocol. The static routing protocol itself has the same high electricity consumption with the bridge protocol and the temperature of the static routing protocol processor is lower than the RIP routing protocol. So that in general the RIP routing is still an eco-friendly data forwarding protocol even though the processor temperature value is still higher than static routing's. For RIP routing protocol, power consumption reaches 7.567 Watt, CPU usage reaches $7.333 \%$, and processor temperature reaches $36.727^{\wedge} \mathrm{C}$.

The interesting thing in this study is bridge protocols using highest energy consumption for both HTML access and video streaming scenario. Starting with the power consumption, CPU usage, until the processor temperature, it gets the highest average value. Although bridge has a simple configuration like plug and play but bridge protocol

Cite: Alhamri, R., Cinderatama, T., Heriadi, A., \& Pradana, A. (2019). Energy Consumption Between Routing and Bridging Protocol for Eco-Friendly Wireless Networks. Kinetik: Game Technology, Information System, Computer Network, Computing, Electronics, and Control, 4(3). doi:http://dx.doi.org/10.22219/kinetik.v4i3.800 

configuration gives more energy consumption rather than routing protocols for every measurement parameters. For routing protocols, generally RIP gives the lower energy consumption than static routing. RIP gives up with static routing only at processor temperature value for video streaming scenario where RIP reaches $36.73^{\wedge} \mathrm{C}$ and static routing reaches $36.37^{\wedge} \mathrm{C}$. It means RIP has more complexity for the algorithm, so that the processor needs to hold more signal that makes the IC in high temperature. Based on the comparison of the value of power consumption, CPU usage, and processor temperature in the protocol used, for the most eco-friendly in HTML access testing scenario is RIP routing protocol. While the protocol used for video streaming access testing scenario is the RIP routing protocol either.

\subsection{HTML Access Scenario Comparison}

HTML access testing scenario run in 150 seconds for each data forwarding protocols, and the comparison of the results for every data forwarding protocols is shown at Figure 4. The highest power consumption in HTML access was when the router using the bridge protocol in seconds to 60 which reached 8.9 Watts. While the lowest consumption was obtained when using RIP routing in seconds to 120 with reaches 5.7 Watts as shown at Figure 4(a). From the test results, the highest CPU usage was when using the static routing protocol in seconds to 50 which reached $13 \%$. While the lowest CPU usage was when using RIP routing protocol in seconds to 20 and 60 which reached $1 \%$ as shown at Figure 4(b). For comparison of processor temperature, the highest temperature was obtained when using the RIP routing protocol in seconds to 90 with a temperature value of $42.9^{\wedge} \mathrm{C}$. While the lowest temperature was obtained by using the RIP routing protocol which reached $32 \cdot 1^{\wedge} \mathrm{C}$ in seconds to 100 as shown at Figure 4(c).



(a). Comparison Chart of Power Consumption

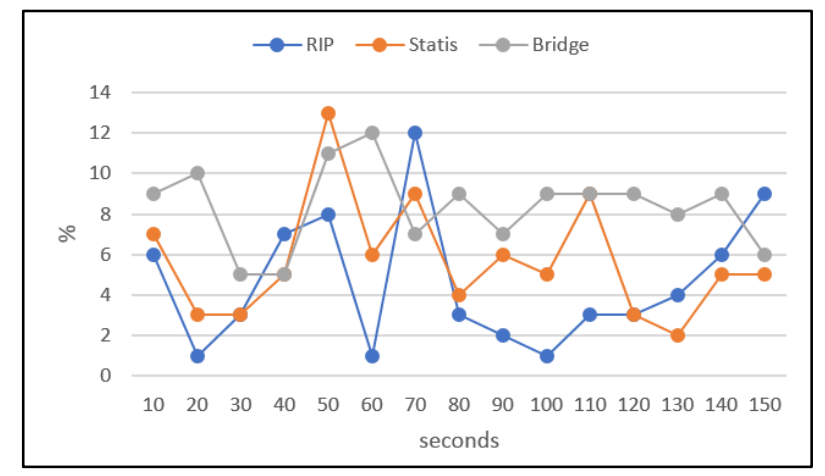

(b). Comparison Chart of CPU Usage

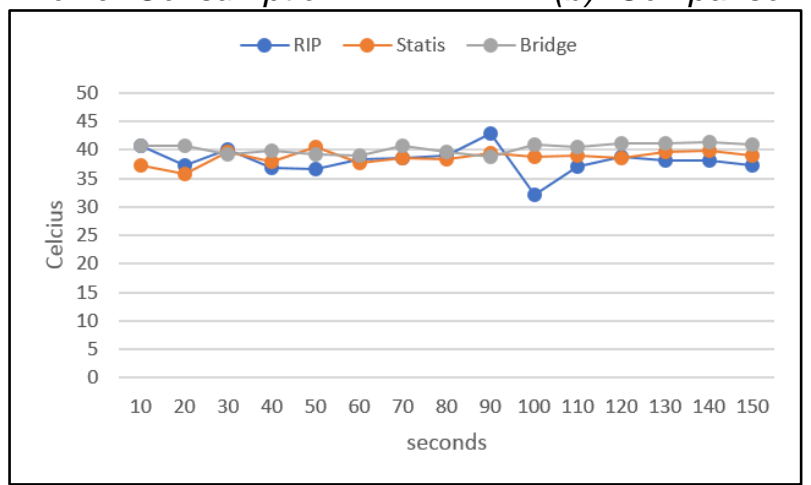

(c). Comparison Chart of Processor Temperature

Figure 4. Comparison Result of HTML Access Scenario

\subsection{Video Streaming Access Scenario Comparison}

Same as early explanation, video streaming access testing scenario runs in 150 seconds for every data forwarding protocols, and the comparison is shown at Figure 5. The highest power consumption was when using the bridge protocol in seconds to 100 which reaches 8.9 Watts. While the lowest use was obtained when using static routing in seconds to 80 with 7.1 Watt as shown at Figure 5(a). For CPU usage, the highest value was when using static routing protocol in seconds to 120 which reached $20 \%$. While the lowest CPU usage value was when using the RIP routing protocol which reached $1 \%$ at 10 seconds and also static routing with a value of $1 \%$ at 60 seconds as shown at Figure 5 (b). For a comparison of processor temperature, the highest temperature value was obtained when using static routing protocols in second to 10 which reached $41^{\wedge} \mathrm{C}$. While the lowest temperature was obtained by using the RIP routing protocol with a temperature which reached $33.2^{\wedge} \mathrm{C}$ in seconds to 40 as shown at Figure $5(\mathrm{c})$. 


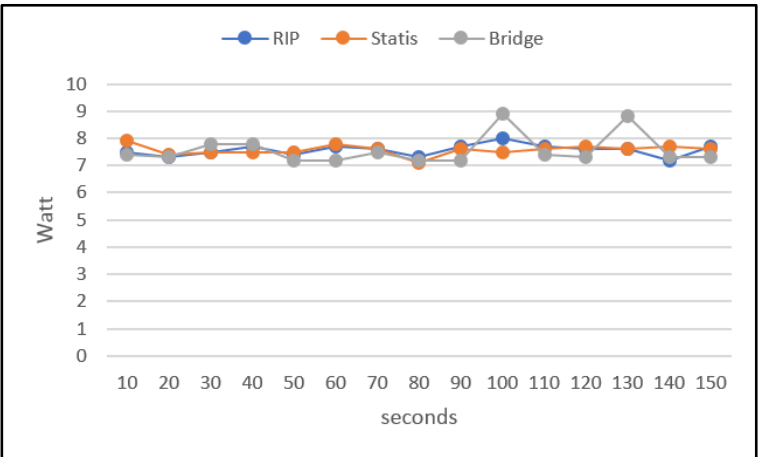

(a). Comparison Chart of Power Consumption



(b). Comparison Chart of CPU Usage

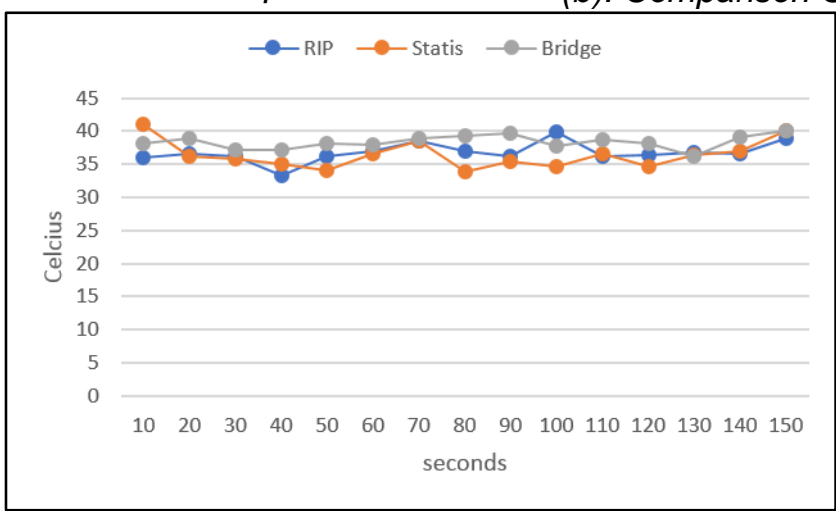

(c). Comparison Chart of Processor Temperature

Figure 5. Comparison Result of Video Streaming Scenario

\section{Conclusion}

From this research, it can be concluded that generally routing protocol used lowest energy consumption than bridging protocol, especially protocol of RIP. It makes sense since RIP can handle forwarding data to the destination host exactly without remains data broadcasting like bridging protocol do. So that, the processor of the network device does not work hard because of data loading. And finally it will affect the power consumption of the network device. Wireless networks has the same way of work with wired networks. By implementing routing protocol for forwarding data to the wireless router device, it can save the energy consumption. For wireless networks with small amounts of the device, the difference of energy consumption actually is not significant. But for large network like wireless WAN it will be significant enough. For the feature research, the focus can be only to routing protocols since they are more significant to save the energy. More complex scenario for the size of data packet also give a different result for energy consumption. So that it can examined more detail about saving energy consumption of the wireless devices.

\section{References}

[1] S. Kemp, "Digital in 2017: Global Overview," We Are Social, 24 January 2017. [Online]. Available: https://wearesocial.com/specialreports/digital-in-2017-global-overview. [Accessed 1 April 2019].

[2] F. Abdi, "Apa itu BTS?," Diskominfo Tabalong, 20 August 2018. [Online]. Available: http://kominfo.tabalongkab.go.id/2018/08/20/apa-itu-bts/. [Accessed 30 Maret 2019].

[3] H. Pihkola, M. Hongisto, O. Apilo and M. Lasanen, "Evaluating the Energy Consumption of Mobile Data Transfer: From Technology Development to Consumer Behaviour and Life Cycle Thinking," Sustainbility, Vol. 10, No. 2494, Pp. 1-16, 2018. https://doi.org/10.3390/su10072494

[4] K. Saidi, H. Toumi and S. Zaidi, "Impact of Information Communication Technology and Economic Growth on the Electricity Consumption: Empirical Evidence from 67 Countries," Journal of the Knowledge Economy, Vol. 8, No. 3, Pp. 789-803, 2015. https://doi.org/10.1007/s13132015-0276-1

[5] B. Han, D. Wang, W. Ding and L. Han, "Effect of Information and Communication Technology on Energy Consumption in China," Natural Hazards, Vol. 84, No. 1, Pp. 297-315, 2016. https://doi.org/10.1007/s11069-016-2188-1

[6] N. C. Horner, A. Shehabi and I. L. Azevedo, "Known Unknowns: Indirect Energy Effects of Information and Communication Technology," Environmental Research Letters, Vol. 11, No. 10, Pp. 1-21, 2016.

[7] C. B. Tunali, "The Effect of Information and Communication Technology on Energy Consumption in the European Union Countries," Journal of Economics and Sustainable Development, Vol. 7, No. 5, Pp. 54-60, 2016.

[8] S. A. Morelli, E. R. Sanchez, S. Sandra and J. Lloret, "Router Power Consumption Analysis: Towards Green Communications," in International Conference on Green Communications and Networking, Gandia, 2012. https://doi.org/10.1007/978-3-642-37977-2_3

[9] J. Baliga, R. Ayre, K. Hinton and R. S. Tucker, "Energy Consumption in Wired and Wireless Access Networks," in Communications Magazine, 2011. https://doi.org/10.1109/MCOM.2011.5783987

Cite: Alhamri, R., Cinderatama, T., Heriadi, A., \& Pradana, A. (2019). Energy Consumption Between Routing and Bridging Protocol for Eco-Friendly Wireless Networks. Kinetik: Game Technology, Information System, Computer Network, Computing, Electronics, and Control, 4(3). doi:http://dx.doi.org/10.22219/kinetik.v4i3.800 
[10] H. Wetskog and T. Winther, "Electricity Consumption: Should There Be a Limit? Implications of People's Attitudes for the Forming of Sustainable Energy Policies," The Journal of Sustainable Development, Vol. 11, No. 1, Pp. 97-114, 2014.

[11] Kardono, "Teknologi Ramah Lingkungan: Kriteria, Verifikasi, dan Arah Pengembangan," BPPT, Jakarta, 2010.

[12] M. Salahuddin and K. Alam, "Information and Communication Technology, Electricity Consumption and economic growth in OECD Countries: A Panel Data Analysis," Electrical Power and Energy Systems, Vol. 76, Pp. 185-193, 2015. https://doi.org/10.1016/j.ijepes.2015.11.005

[13] Z. Yan, R. Shui and Z. Yang, "ICT Development and Sustainable Energy Consumption: a Perspective of Energy Productivity," Sustainability, Vol. 10, No. 2568, Pp. 1-15, 2018. https://doi.org/10.3390/su10072568

[14] L. M. Feeney and M. Nillson, "Investigating the Energy Consumption of a Wireless Network Interface in a Ad Hoc Networking Envionment," in IEEE INFOCOM, Alaska, 2001. https://doi.org/10.1109/INFCOM.2001.916651

[15] J. Ahn and H. S. Park, "Measurement and Modeling the Power Consumption of Router Interface," in 16th ICACT, Pyeongchang, 2014. https://doi.org/10.1109/ICACT.2014.6779082

[16] J. T. Yu, "DePaul University," 29 March 2004. [Online]. Available: facweb.cti.depaul.edu/jyu/Publications/Yu-Linux-TSM2004.pdf. [Accessed 1 March 2019].

[17] A. Systems, "Albentia," 1 May 2010. [Online]. Available: www.albentia.com/Docs/WP_EN/ALB-W-000007enA1_BridgingvsRouting.pdf. [Accessed 1 March 2019].

[18] F. S. Dadah, A. Ore-Ofe, A. D. Usman, Y. A. Mshelia and M. O. Babatunde, "An Election Energy Threshold Based Multi-Hop Routing Protocol in a Grid-Clustered Wireless Sensor Network," Kinetik, Vol. 3, No. 4, Pp. 327-336, 2018. http://dx.doi.org/10.22219/kinetik.v3i4.661

[19] R. Perlman, "IETF," 19 December 2014. [Online]. Available: https://www.ietf.org/slides/slides-edu-routing-bridging-switching-02.pdf. [Accessed 1 March 2019].

[20] J. Jimenez, O. Romero, J. Lloret and J. Diaz, "Energy Savings Consumption on Public Wireless Networks by SDN Management," Mobile Networks and Applications, Vol. 24, No. 2, Pp. 667-677, 2016. https://doi.org/10.1007/s11036-016-0784-7

[21] J. Jimenez, O. Romero, J. Lloret and J. Diaz, "Energy Savings Consumption on Public Wireless Networks by SDN Management," Mobile Networks and Applications, Vol. 24, No. 2, Pp. 667-677, 2016. https://doi.org/10.1007/s11036-016-0784-7

[22] D. S. Jacome, A. Rego, S. Sendra and J. Lloret, "Energy Consumption in Software Defined Networks to Provide Service for Mobile Users," in 13th IWCMC, Valencia, 2017. https://doi.org/10.1109/IWCMC.2017.7986498

[23] wndw, "Wireless Networking in the Developing World," 15 April 2013. [Online]. Available: http://www.wndw.net/book.html. [Accessed 1 March 2019].

[24] J. Ross, The Book of Wireless Second Edition, No Starch Press, 2008.

[25] T. Carpenter, Certified Wireless Technology Specialist Study Guide, Mc Graw-Hill, 2010

[26] M. Travers, "CPU Power Consumption Experiments and Results Analysis of Intel i7-4820K," Newcastle University, Newcastle, 2015.

[27] A. Telecom, "Ethernet RFC 2544 Explained: In Networking and Telecoms," Albedo Whitepaper, Barcelona, 2013. 